\title{
Chlamydia trachomatis infection: host immune responses and potential vaccines
}

\author{
L Hafner ${ }^{1}, K_{\text {Beagley }}^{2}$ and P Timms ${ }^{2}$
}

Chlamydia trachomatis causes genital tract infections that affect men, women, and children on a global scale. This review focuses on innate and adaptive immune responses in the female reproductive tract (FRT) to genital tract infections with $C$. trachomatis. It covers $C$. trachomatis infections and highlights our current knowledge of genital tract infections, serovar distribution, infectious load, and clinical manifestations of these infections in women. The unique features of the immune system of the FRT will be discussed and will include a review of our current knowledge of innate and adaptive immunity to chlamydial infections at this mucosal site. The use of animal models to study the pathogenesis of, and immunity to, Chlamydia infection of the female genital tract will also be discussed and a review of recent immunization and challenge experiments in the murine model of chlamydial FRT infection will be presented.

\section{CHLAMYDIAL GENITAL TRACT INFECTIONS Epidemiology}

Sexually transmitted diseases (STDs) are a major global cause of acute illness, infertility, long-term disability, and death, with severe medical and psychological consequences for millions of men, women, and children. The World Health Organization (WHO) states that "in developing countries, STDs and their complications are amongst the top five disease categories for which adults seek health care. In women of childbearing age, STDs (excluding HIV) are second only to maternal factors as causes of disease, death and healthy life lost." The presence of an untreated STD can also "increase the risk of both acquisition and transmission of HIV by a factor of up to $10 . " 1$ Untreated infection with C. trachomatis is also associated with productivity losses forming a substantial portion of the economic burden of disease. ${ }^{2}$

As of July 2007, the most recent international estimates are that 340 million new cases of STD infections occurred worldwide in 1999 of which around 92 million were chlamydial infections affecting more women (50 million) than men. The prevalence of Chlamydia in adults (persons between 15 and 49 years of age) also varies across the world and is highest for females (24 million) and males (19 million) in South-East Asia followed by adults (15.8 million) in sub-Saharan Africa. The highest rate (119) of new cases of infected adults per 1,000 population has occurred in sub-Saharan Africa. ${ }^{1}$

Chlamydia remains the most commonly reported infectious disease in the United States. In 2005, there were 976,445 cases of genital Chlamydia trachomatis infections reported ${ }^{3}$ with 496.5 cases per 100,000 population in women and 150 cases per 100,000 population in men. Even so, most Chlamydia cases go undiagnosed with approximately $70 \%$ of chlamydial endocervical infections in women and $50 \%$ of chlamydial urethral infections in men being asymptomatic. ${ }^{4,5}$ It is estimated that there are approximately 2.8 million new cases of Chlamydia in the United States each year. ${ }^{6}$ In addition to gender, age and race are risk factors for genital chlamydial infections. Among women, the highest age-specific rates were among the 15- to 19 -year-olds (2,796.6 cases per 100,000 females) and 20 - to 24 -year-olds (2,691.1 cases per 100,000 females). The rate of Chlamydia among blacks was over eight times higher than that of whites (1,247 and 152.1 cases per 100,000 , respectively). ${ }^{3}$

\section{C. trachomatis infection}

In vivo, the intracellular, biphasic developmental cycle of the Gram-negative bacterium C. trachomatis is reliant on host cell ATP and nutrients for its existence. In this unique cycle, the bacterium is normally found in two highly specialized morphologic forms - the extracellular, metabolically inactive, and infectious elementary body (EB) and the metabolically active, intracellular form known as the reticulate body (RB) that divides by binary fission within the inclusion (reviewed in ref. 7). The infectious EB enters the mucosal host cells in a process now known to be independent of host cell-surface

\footnotetext{
${ }^{1}$ Department of Life Sciences, Queensland University of Technology, Brisbane, Queensland, Australia. ${ }^{2}$ Institute of Health and Biomedical Innovation, Queensland University of Technology, Brisbane, Queensland, Australia. Correspondence: L Hafner (I.hafner@qut.edu.au)

Received 8 July 2007; accepted 6 December 2007; published online 9 January 2008. doi:10.1038/mi.2007.19
} 
heparin sulfate glycosaminoglycans ${ }^{8}$ and following binding to a number of proposed ligands on Chlamydia (reviewed in ref. 9). Once inside, the epithelial cell-surface antigens of the EB appear to prevent fusion of the endosome with lysosomes, ${ }^{10}$ allowing the EB to subsequently reorganize into the larger, replicative form of the RB. RBs successfully divide by binary fission, filling the endosome that has now become a chlamydial cytoplasmic inclusion. Multiplication then ceases after $48-72 \mathrm{~h}$ and nucleoid condensation occurs, enabling the RBs to transform into infectious EBs. The EBs are released from the cell and target new host cells for progression of infection. ${ }^{11}$

In females, Chlamydia targets the apical surface of polarized superficial columnar epithelial cells that are found lining the endocervix and upper reproductive tract, an attachment that has previously been shown to be enhanced in estrogen-dominant endometrial epithelial cells. ${ }^{12}$

Chlamydiae have the ability to cause prolonged and often subclinical infection. In vitro, it can be demonstrated that Chlamydia can enter a latent state under stressful conditions such as exposure to interferon (IFN)- $\gamma$ (which depletes available tryptophan), exposure to penicillins, ${ }^{13}$ growth in non-permissive cells, ${ }^{14}$ or iron depletion. ${ }^{15}$ This third or "persistent form" has been defined as a viable but non-cultivable growth stage, resulting in a longterm relationship with the infected host. ${ }^{16}$ Persistence allows C. trachomatis to remain dormant in the host cell, but after the removal of stressful conditions, C. trachomatis can subsequently be recovered from culture. There is also accumulating evidence to support chlamydial persistence in vivo. ${ }^{17-21}$ However, direct detection of Chlamydiae for the diagnosis of persistent latent infection is somewhat questionable, and thus chlamydial persistence is not accepted by all researchers in the field, as many believe that to demonstrate that chlamydial persistence occurs in vivo, both nucleic acid detection and viability of the organism need to be proved. It is known that serological diagnosis of chronic persistent, latent infection can be somewhat imprecise because of low detectable levels of specific antibodies, although recently it was reported that even very low levels of specific antibodies may be directly associated with a persistent infection. ${ }^{22}$ How often persistence occurs in vivo is unknown, but it may be that this persistence acts as an adaptive survival mechanism for the organism. A review on chlamydial persistence has recently been published. ${ }^{23}$

\section{Serovar distribution, clinical manifestations, and infectious load}

The major outer membrane protein (MOMP) and its gene ompA of C. trachomatis is an antigenically diverse and abundant protein found on the surface of the organisms. Chlamydial strains causing sexually transmitted infections are differentiated into individual serovars by typing with an antiMOMP monoclonal antibody using microimmunofluorescence, enzyme immunoassay or, more recently, by typing using PCR and reverse line blot hybridization assay. ${ }^{24,25}$ Serovars D, Da, E, F, G, H, I, Ia, J, and K are responsible for urogenital infections. The predominant strains of C. trachomatis that are most prevalent worldwide are serovars E, F, D, and Ia. ${ }^{26-32}$ Serovar E is the predominant serovar in cervical isolates ${ }^{33}$ and urine samples ${ }^{34}$ but was found in only $6 \%$ of rectal isolates. ${ }^{33}$

Individual serovars have been reported to differ among different groups of women ${ }^{35}$ by geographic region ${ }^{32}$ and also by specific racial groups. ${ }^{36}$ Asymptomatic C. trachomatis infections are highly prevalent in young women, with genotyping results showing that serovars E, I, and D (in decreasing order) were frequent in women aged less than 30 years, whereas serovars $\mathrm{F}, \mathrm{E}$, and $\mathrm{G}$ (in decreasing order) were found in a group of randomly selected patients (aged 17-68 years) attending an inner-city outpatient gynecological clinic. ${ }^{35}$ Significant differences in serotype distribution by geographic region in the United States were reported, with the rare serotypes Ba and G significantly overrepresented in San Francisco. ${ }^{32}$ A more recent study reported that blacks were less often infected with serovars E (30 vs. $41 \%)$ and J (9 vs. $24 \%$ ) but more often infected with serovar Ia (17 vs. $0 \%)$ when compared with individuals of other racial groups. ${ }^{37}$

The association between serovars and infectious load was also recently investigated. Similar infectious loads were reported for high-(E, F, and G) and low-(Ia, H, J, and Ja) prevalence serovars, suggesting a similar ability for in vivo replication despite their differing ecological successes. ${ }^{38}$ Men had a significantly lower load than women when the genotype was $\mathrm{F}$, and the probability of being infected with serovar J was 7.7 -fold higher in patients with prior chlamydial infections. ${ }^{38}$

\section{Current antimicrobial therapy}

Current recommendations of Centers for Disease Control (CDC) for the treatment of C. trachomatis urethritis and cervicitis are comprehensively covered in a recent review. ${ }^{39}$ Compliance with an effective antibiotic regimen has nevertheless reportedly been associated with an increased frequency of recurrent infection, ${ }^{20,40}$ tubal infertility, ${ }^{17}$ and persistent infection characterized by a non-culturable but viable state in which RBs do not mature into EBs. ${ }^{29,41}$ An in vitro study of latent genital chlamydial infections using polarized human endometrial epithelial cells reported that a persistent form of C. trachomatis did not have the same susceptibility to antibiotics as compared with actively growing Chlamydiae, with persistent Chlamydiae phenotypically resistant to azithromycin. ${ }^{42}$ It has recently been hypothesized that women with high chlamydial loads may be at increased risk of antibiotic treatment failure, ${ }^{43}$ as it is known that at high multiplicities of infection (load), in vitro resistance can often be demonstrated to antimicrobials and genital load is probably greater in women than men.

\section{Disease sequelae and immunopathogenesis}

The initial C. trachomatis infection at the mucosal site may, over time, extend from the cervix via the endometrium and into fallopian tubes in some individuals who do not spontaneously clear the initial chlamydial infection. Chronic disease associated with bacterial persistence, inflammation, and tissue damage are common sequelae of infection with these organisms. The 
disease sequelae caused by ascending C. trachomatis infections include pelvic inflammatory disease (PID), ectopic pregnancy, and tubal factor infertility (TFI), virtually all as a result of chronic inflammation that causes fibrosis and scarring that characterize chlamydial diseases. C. trachomatis reportedly is responsible for approximately $25 \%$ of the greater than one million cases of PID per year in the United States. It has also been documented that one in four women infected with C. trachomatis has unrecognized or latent or "silent" PID that can lead to fallopian tube damage. ${ }^{44}$ Chlamydial infections may also be linked to cervical cancer ${ }^{45,46}$ and may also increase susceptibility to, and transmission of, HIV in women. ${ }^{47}$

Immunopathogenesis of Chlamydia disease is currently unclear. It has been proposed that persistent infections leading to chronic inflammation and tissue damage can result from interleukin-10 (IL-10) downregulation of chlamydial-specific T-cell responses. ${ }^{48}$ Murine model studies of chlamydial genital tract infections have shown that neutrophil recruitment and activation of matrix metalloproteinase (MMP)-13, MMP-10, MMP-15, MMP-17, MMP-3, MMP-9, and MMP-12 occur during acute infection ${ }^{49}$ and correlate directly with hydrosalpinx formation and infertility ${ }^{50}$ and that inhibiting MMPs protects mice against chronic disease manifestations. ${ }^{51}$

The issue of whether chlamydial PID is a consequence of persistent infection, immunopathology, or infection linked to the initiation of autoimmunity ("molecular mimicry") remains unresolved (for a review on Chlamydia and antigenic mimicry, see ref. 52). The phenomenon of molecular mimicry involves products of genes conserved in the host and infecting bacteria, e.g., heat-shock protein 60 (HSP60), or protein products from dissimilar genes sharing similar structures that elicit an immune response to both self- and microbial proteins. Chlamydial proteins that mimic host self-proteins include chlamydial heat-shock protein 60 (CHSP60), ${ }^{53}$ the DNA primase of C. trachomatis, and the OmcB proteins. ${ }^{54} \mathrm{CHSP} 60$ is considered a key antigen in the immunopathogenesis of TFI, ${ }^{55-57}$ stimulating both humoral and cell-mediated immune (CMI) responses in women with PID or TFI. Indeed, a recent report shows that the TFI prediction model can be improved by combining tests for humoral and CMI responses to CHSP $60 .{ }^{58} \mathrm{~A}$ recent study reported that expression of CHSP60 is greatly enhanced in C. trachomatis serovar E propagated in an iron-deficient medium, a stress-inducing growth condition that can result in persistent forms of Chlamydia. ${ }^{59}$ Infertility in women has also been associated with the presence of CHSP $10 .{ }^{60,61}$ A recent study investigated whether host genetic traits (carrying multiple single-nucleotide polymorphisms in different genes) in the bacterial sensing system played a role in C. trachomatis-associated TFI. The investigators reported that, following a $C$. trachomatis infection, subfertile women (i.e., those with reduced fertility with prolonged time of unwanted non-conception) carrying multiple single-nucleotide polymorphisms in four C. trachomatis pathogen recognition receptor genes (Toll-like receptor (TLR)9, TLR4, CD14, and CARD15/NOD2) were at increased risk of tubal pathology. 62

\section{FEMALE REPRODUCTIVE TRACT AND IMMUNE RESPONSESTO CHLAMYDIA}

\section{Unique features of the immune system}

The mucosal immune system of the female reproductive tract (FRT) comprises compartments that are unique from those found at other mucosal and systemic immune sites. The FRT contains key cells of both the innate and adaptive immune systems that detect and respond to invading microbial pathogens, and these cells are found throughout the vagina, cervix, uterus, and fallopian tubes. Protective cells include polarized epithelial cells of the endocervix, uterus and fallopian tubes, macrophages and neutrophils, and natural killer (NK) cells in the uterus, although NK cells (or large granular lymphocytes) are localized throughout the FRT in large numbers but particularly within the endometrium. ${ }^{63}$ Many distinct immunological features are found in the mucosal tissues of the FRT. Mucosal inductive sites are lacking in the FRT, although unusual menstrual cycle-dependent aggregates of CD8 cells and B cells occur in the endometrium. ${ }^{64}$ In contrast to the dominant role of IgA-producing cells at other mucosal sites, the dominant immunoglobulin isotype in the genital tract is IgG. ${ }^{65}$ The epithelial cells in the endometrium can constitutively express major histocompatibility complex class II and function as antigen-presenting cells, at least for reactivation of memory $\mathrm{T}$ cells. This latter antigen presentation is hormonally regulated.

\section{Innate immunity}

The innate immune system of the FRT has evolved to recognize molecular patterns (rather than antigens) on microbial invaders that are not normally found on the host. It relies on receptors that recognize conserved pathogen-associated molecular patterns found in certain microorganisms. ${ }^{66}$ The pattern recognition receptors of the host that recognize pathogen-associated molecular patterns are expressed on cells of the innate immune system. TLRs are one group of pattern recognition receptors that are expressed on macrophages, dendritic cells (DCs), neutrophils, NK cells, and epithelial cells. Comprehensive reviews on innate and adaptive immunity in the FRT $^{63}$ and epithelial cells as sentinels in immune protection ${ }^{67}$ have recently been published.

There are many reports on the innate immune responses to genital tract infections caused by $C$. trachomatis (for a recent review, see ref. 68). Innate immune responses to chlamydial infection of HeLa cells have been reported to differ between serovars E and L2 of C. trachomatis. ${ }^{69}$ Using human epithelial cell lines, it has been reported that these cell lines fail to respond to lipopolysaccharide (LPS) (associated with absence of surface expression of CD14), indicating that non-TLR4 ligands are involved in the inflammatory response of epithelial cells to Chlamydia. ${ }^{70}$ These data agree with the finding of Rasmussen et al. ${ }^{71}$ that chlamydial LPS is not the component responsible for induction of the proinflammatory cytokines that upregulate the endogenous inhibitors of nuclear factor- $\kappa \mathrm{B}$. The latter component of the innate immune system is a transcription factor that is activated in response to chlamydial components. ${ }^{72,73}$ 
Experiments using TLR adaptor molecule myeloid differentiation factor 88 (MyD88)-deficient mice have demonstrated the importance of TLRs in the generation of adaptive immune responses. ${ }^{74}$ TLR2 has been identified as the principal TLR responsible for the secretion of IL- 6 and granulocyte-macrophage colony-stimulating factor in a MyD88-dependent manner in Chlamydia muridarum-infected cloned murine oviduct epithelial cell lines. ${ }^{75}$ It has also been reported that the surface-exposed TLR2 plays a prominent role in the recognition process of $C$. muridarum infection but that the time course of genital infection was unaffected by the absence of TLR2, although significant reduction in oviduct pathology was noted in TLR2-knockout mice. ${ }^{76}$ Mice deficient in MyD88 showed greater effects on clearance of C. muridarum genital infection in vivo and in vitro, demonstrating a prominent role for MyD88 in the induction of IFN- $\gamma$-inducible protein and IFN- $\beta$ during chlamydial infection in a TLR2- and TLR4-independent manner. ${ }^{77}$ This lack of involvement of TLR4 in the $C$. muridarum model of female urogenital chlamydial infection is largely substantiated by recent data showing a lack of involvement of CD14 (an accessory protein for TLR4 recognition) in pathogenesis in this model. ${ }^{78}$ It has also been reported from studies with the $\mathrm{L} 2$ serovar of $C$. trachomatis that intracellular TLR2 and MyD88 are colocalized within the chlamydial inclusion and that expression of TLR2 was required for IL-8 secretion from infected cells. ${ }^{79}$ In a murine model of chlamydial genital tract infection, it has also recently been reported that TLR3, or an unknown pattern recognition receptor using the Toll/IL-1R domain-containing adaptor inducing IFN- $\beta$, is responsible for IFN- $\beta$ production by $C$. muridarum-infected oviduct epithelial cells. ${ }^{80}$

DCs, which survey epithelial surfaces, and NK cells are important components of the innate immune system. Human NK cells can lyse C. trachomatis-infected epithelial cell lines. ${ }^{81}$ Epithelial cells, the primary targets of $C$. trachomatis infection, produce IL-18 in response to infection and DCs produce IL-12, and it has been reported that these factors then act together to induce IFN- $\gamma$ production from NK cells. ${ }^{82}$ The production of substantial amounts of IFN- $\gamma$ favors the differentiation of T helper 1 (Th1) cells, further maximizing IFN- $\gamma$ production that is crucial for resolving chlamydial infection. In addition to the type II IFN $-\gamma$, it is also known that type I IFNs have protective effects against C. trachomatis infections by increasing tryptophan degradation in synergism with tumor necrosis factor, IL-1, and LPS. ${ }^{83}$ For a comprehensive review of type I IFN activity against bacterial infections, see ref. 84 .

\section{Adaptive immunity}

An effective protective immune response to pathogens requires not only innate immunity, the first line of defense to prevent and control invasion of pathogens, but is also dependent upon adaptive immunity. The innate recognition of infection can lead to the induction of adaptive immune responses through both pathogen-associated molecular pattern-dependent and pathogen-associated molecular pattern-independent activation of DCs. ${ }^{85}$
It is well known that some elements of adaptive immunity in the genital tract are distinct and unique from other mucosal sites. ${ }^{86-88}$ There is also evidence that the acquired immune systems in some sites (e.g., endometrium, fallopian tube, and occasionally the endocervix) and other sites (vagina, ectocervix, and occasionally the endocervix) respond differentially to chlamydial challenge with different $\mathrm{T}$-cell recruitment patterns throughout the reproductive tract during infection. ${ }^{89}$

\section{Humoral immunity}

Humoral immunity in the FRT is reliant on the IgG- and IgAsecreting plasma cells that are found in greater abundance in the endocervix than in the vagina. In contrast to other mucosal secretions, the dominant immunoglobulin isotype is IgG rather than secretory immunoglobulin A found in the cervico-vaginal fluid of the female genital tract. ${ }^{65}$

In murine models, B cells or specific anti-chlamydial antibody responses that may enhance protective $\mathrm{T}$-cell responses in the FRT have been recorded following genital chlamydial infections, ${ }^{89-93}$ although mice incapable of producing specific antibody resolve primary chlamydial genital infection and are resistant to reinfection. ${ }^{90,94}$ Moore et al. ${ }^{95}$ report that in vitro anti-chlamydial antibodies increase the rate of Th1 activation by $\mathrm{FcR}^{+/+}$but not $\mathrm{FcR}^{-1-}$ antigen-presenting cells, results that provide a mechanistic basis for the need for both T-cell and humoral immune responses in protective immunity to chlamydial reinfection. The results suggest that a major role for antibodies in chlamydial immunity is the enhancement of Th1 activation via FcR-mediated processes involving DCs. A recent study using the C. muridarum model of chlamydial genital tract infection reported that monoclonal antibodies to the chlamydial MOMP and LPS conferred significant levels of immunity to reinfection and reduced chlamydial shedding by over 100 fold. ${ }^{96}$ These data of Morrison and Morrison ${ }^{96}$ do not support the notion that direct neutralization is a major mechanism of antibody-mediated protection against chlamydial infection in vivo, but these authors suggest that antibody-dependent cellular cytotoxicity mechanisms are involved in protection. In a more recent study, ${ }^{97}$ however, it was reported that mice genetically deficient in Fc receptors $\left(\mathrm{FcR}^{-1-}\right)$ resolved primary infection and secondary reinfection in a manner indistinguishable from $\left(\mathrm{FcR}^{+/+}\right)$wild-type cells. These recent data imply that FcR-mediated interactions are not the only mechanism by which antibody confers protective immunity to reinfection.

Anti-chlamydial antibody responses (MOMP-specific IgA and IgG in vaginal and uterine lavage fluid and MOMP-specific IgA in serum) have been reported following various immunization routes such as transcutaneous, intranasal, ${ }^{98-102}$ and systemic ${ }^{100,103,104}$ immunizations, using animal models of chlamydial genital tract infection.

Antibodies are induced and present in the genital tract secretions following C. trachomatis infection, and the immunoprotective role of antibody-mediated immunity has been well reported (and debated) in the literature. Antibody has been shown to contribute to a protective response against genital tract reinfection with C. trachomatis. ${ }^{105}$ Indeed, antibody has demonstrated 
many beneficial effects against many infectious agents, including Chlamydia, in which CMI would be assumed to represent the key protective mechanism. $.33,105,106$ However, owing to the many chlamydial challenge doses that are used by different investigators, the exact role of antibody in protection against chlamydial infection is difficult to assess.

\section{CMI}

CMI is the predominant component of protective immune responses to Chlamydia, with the generation of specific major histocompatibility complex class II-restricted $\mathrm{CD} 4^{+} \mathrm{T}$ cells playing a central role both by responding to, or by orchestrating, the activation of other protective immune components. It is the Th1 subpopulation of CD4 cells that is responsible for resolving chlamydial genital infection via an effector cytokine response, although other components such as $\mathrm{CD} 8^{+} \mathrm{T}$ cells also play a role. ${ }^{107-109}$ The protective CMI response is strongly associated with the production of IFN- $\gamma$ either by $\mathrm{CD} 4^{+}$or by $\mathrm{CD} 8^{+} \mathrm{T}$ cells. ${ }^{110-112}$ A recent review on T-cell responses to $C$. trachomatis infection has been published. ${ }^{113}$

DCs are present in the cervix and vagina of humans, mice, and macaques ${ }^{114-116}$ and are central in T-cell priming and the induction of chlamydial-specific immunity. The form of Chlamydia initially encountered by DCs and the hormonal status at the time of this encounter may influence the type of adaptive immune response (protective vs. inflammatory) that is elicited by infection. Shaw et al. ${ }^{117}$ showed that adoptive transfer of DCs pulsed with non-viable Chlamydia into naive mice afforded significant protection against subsequent challenge with viable Chlamydia. In a study investigating the uptake and processing of C. trachomatis serovar L2 by human DC, it was shown using bloodderived myeloid DCs that the entry of $C$. trachomatis could be inhibited by heparin, that activated DC produced IL-12 and tumor necrosis factor- $\alpha$, but not IL-10, in DCs infected with Chlamydia vacuoles did not develop into inclusion bodies, and that infected DCs efficiently presented chlamydial antigens to CD4 + T cells and expanded C. trachomatis-specific CD8 + T cells. ${ }^{118}$ Adoptive transfer of live-EB-pulsed bone marrowderived DCs was more effective than that of UV-EB-pulsed $\mathrm{DC}$ at protecting mice against intranasal challenge with live $C$. muridarum, ${ }^{119}$ and genetic profiling of DCs exposed to live or inactivated EBs revealed marked differences in the expression of cysteine-X-cysteine chemokines. ${ }^{120}$

In C. trachomatis-positive infertile women, the recruitment of lymphocyte subsets in the genital tract and subsequent production of Th1 and Th2 cytokines in the cervical secretions and laparoscopic specimens from the fallopian tubes were recently evaluated. Flow cytometric analysis of cervical secretions in these women revealed that the recruitment of both CD4 and CD8 lymphocytes to the genital tract was upregulated and that a variation in the production rates of different cytokines in the cervical secretions and fallopian tubes was observed. ${ }^{121}$ These results suggest that CD8 lymphocytes may be important for local regulation of Th1/Th2 responses in the genital tract during C. trachomatis infection, and this would be supported by the results of Yeaman et al. ${ }^{64} \mathrm{~A}$ recent comprehensive analysis was undertaken investigating in vivo cytokine responses to chlamydial infections in a large cohort of high-risk female adolescents before and after acquisition and before and after clearance of chlamydial infection. An increase in the endocervical production of the Th1-associated cytokine IL-12 and a decrease in IL-2 concentrations in endocervical secretions coincided closely with genital C. trachomatis infection. ${ }^{122}$ Decreased local T-cell response and IFN $-\gamma$ production may promote latent C. trachomatis infection and inflammation or immunopathology. ${ }^{113}$ It has recently been hypothesized that IL-12 acts with other host factors to influence the recruitment of effector T lymphocytes to the infected FRT. ${ }^{107}$

The development of Chlamydia-specific T-cell receptor transgenic mice has (for the first time) enabled monitoring of C. trachomatis-specific T-cell responses in the genital mucosa. Using this model, it was reported that after a primary uterine infection with human C. trachomatis serovar L2, naïve Chlamydiaspecific CD $4+\mathrm{T}$ cells developed into Th1 effector cells in the lymph nodes, draining the genital tract in response to infection. Activated $\mathrm{T}$ cells migrated into the genital mucosa and secreted IFN- $\gamma$. ${ }^{123}$

Roan and Starnbach ${ }^{124}$ have also generated a model using retrogenic mice that express a T-cell receptor specific for Chlamydia-specific T-cell antigen CrpA. This model has been used to identify and track the activity of Chlamydia-specific $\mathrm{CD} 8+\mathrm{T}$ cells in vivo. They reported that Chlamydia-specific retrogenic $\mathrm{T}$ cells proliferated in draining lymph nodes and then migrated to the epithelium following genital infection with human C. trachomatis serovar L2.

Results of studies on the immune response to chlamydial infections in relevant animal models indicate that CD4 is the critical T-cell element in the protective immune response in all of these models and that variations in the degree of protective response may result from modulation of the CD4 T-cell effector functions. ${ }^{125}$ During a primary genital infection with C. muridarum, CD4 cells are recruited mainly to the upper genital tract. ${ }^{89}$

T-cell responses in the FRT may be affected by hormonal status at the time of infection by the effects of estradiol and progesterone, either directly on T cells or indirectly on DCs or epithelial cells.

\section{ANIMAL MODELS FOR STUDYING CHLAMYDIAL INFECTION OFTHE FEMALE GENITALTRACT}

To study both the pathogenesis of and immunity to Chlamydia infection of the female genital tract, a number of animal species and chlamydial strains have been used. The most common is the murine model (using either C. muridarum or C. trachomatis human biovars), but the guinea-pig, rat, primate, and pig models are also used. ${ }^{126-128}$

It is known that the female mouse genital tract is susceptible both to the mouse pneumonitis biovar of $C$. trachomatis (i.e., C. muridarum) and to infection with human serovars of C. trachomatis (particularly serovars A, D, E, and L2). In both models, infection and disease outcomes are reportedly enhanced following pretreatment of animals with progesterone. ${ }^{129}$ When 
human serovars are used, the inoculum is administered directly into the upper genital tract tissues using surgical techniques ${ }^{130}$ or it is inoculated intravaginally. ${ }^{131}$ In a study on the course of outcome of infection in female outbred CF-1 mice infected with C. muridarum or human oculogenital isolates of $C$. trachomatis (serovars D, E, F, G, H, I, and K), a more rapid production and release of inclusion-forming units (IFUs) was reported for $C$. muridarum when compared to human serovar $\mathrm{D},{ }^{126}$ although in $\mathrm{C} 3 \mathrm{H}$ mice the course of infection with a strain of serovar $\mathrm{E}$ has been shown to cause more invasive disease. ${ }^{131,132}$

C. muridarum is much more virulent in mice than the human strains, and following vaginal inoculation, it results in an infection that naturally ascends from the lower genital tract (vagina and cervix) to infect the upper genital tract tissues (uterine horns and oviducts). ${ }^{108,133}$ Human serovars cause post-infection sequelae in mice only when high doses are inoculated directly into the uterine horns, resulting in hydrosalpinx formation and infertility, ${ }^{130}$ whereas infection by intravaginal instillation with human serovars normally resolves without these outcomes. ${ }^{131}$ It has also been shown recently (in $\mathrm{C} 3 \mathrm{H} / \mathrm{HeN}$ mice) that prior intravaginal infection of mice with a human serovar E ( $\left.10^{6} \mathrm{IFU}\right)$ may lead to partial protective immunity against challenge infection with serovar A or L2, as shown by reduced chlamydial shedding and a shortened infection course. ${ }^{132}$ It was also reported that homotypic secondary challenge resulted in an increased pathological outcome, with 6 of the 10 mice challenged with serovar $E$ in the secondary infection becoming infertile. ${ }^{132}$ The pathology of the upper genital tract of C. muridarum-infected mice is comparable to that of women with post-chlamydial infection sequelae. ${ }^{108,134}$ It was reported by Ramsey et al. that intraluminal occluding fibrosis of the oviduct is an outcome of genital infection with C. muridarum in $\mathrm{C} 3 \mathrm{H} / \mathrm{HeN}$ mice, ${ }^{49}$ further supporting the use of this murine model to study the pathogenesis of chlamydial upper genital tract infection. However, it is also argued that investigating cytokine profiles in the murine genital tract during the course of infection with human biovars of $C$. trachomatis is potentially more clinically relevant than using the C. muridarum biovar. ${ }^{135}$ The results of a comprehensive study using human and mouse cell lines to provide a better understanding of the innate host defense against infection by mouse-adapted (C. muridarum) and human-adapted (C. trachomatis serovar L2) chlamydial strains have been recently published and conclude that cytokine- and LPS-inducible effectors produced by human and mouse cells differ and, importantly, these responses result in chlamydial strain-specific antimicrobial activities. ${ }^{136}$

Improved mouse models for human chlamydial infection have been suggested based on current knowledge of host-specific IFN $-\gamma$ effector activities against human serovars and $C$. muridarum. Although both C. trachomatis and C. muridarum infect and develop normally in most murine cell lines, their growth is differentially affected following the treatment of cells with IFN- $\gamma ; C$. trachomatis growth is inhibited, whereas $C$. muridarum is resistant. ${ }^{136,137}$ In human epithelial cells, IDO (indoleamine 2,3-dioxygenase) is induced by IFN- $\gamma^{138}$ and it inhibits growth of sexually transmitted infectious (STI) serovars of C. trachomatis by depleting intracellular tryptophan pools. ${ }^{139}$ The ability to synthesize tryptophan from indole may be a major pathogenic mechanism enabling genital chlamydial strains to evade IDO activity. It is known that the LifA domain of C. muridarum cytotoxins targets mouse innate immune effectors such as p47GTPases ${ }^{137}$ and these are mouse-specific proteins. It has recently been predicted, therefore, that a combination of GTPase-knockout, IDO transgenic mouse would be a superior model for the study of human STI using C. trachomatis challenge strains. ${ }^{140}$

To evaluate potential chlamydial vaccine candidates, it is important that the infecting dose used closely approximates the natural infecting dose in the animal model used to evaluate the protective capacity of the vaccine. As sexual transmission of Chlamydia has been demonstrated only in the guinea-pig model of genital tract chlamydial infection with the chlamydial agent of guinea-pig inclusion conjunctivitis (Chlamydophila caviae), this is a reliable and predictable model to use for vaccine studies. ${ }^{141}$ Recently, it has been reported that female guinea-pigs received approximately $10^{2} \mathrm{IFU}$ by sexual transmission and that those infected by the natural route of sexual transmission shed organisms for a significantly shorter time than artificially infected animals. ${ }^{142}$ Guinea-pigs are therefore a useful model for studying vaccine candidates for chlamydial genital tract infections.

Female pig-tailed macaque monkeys have been used by some investigators as a primate model of PID. ${ }^{143-148}$ Male macaques have also been used to identify $C$. trachomatis serovar L2 protein antigens (p242 and TroA localized to intracellular development forms) recognized in the context of infection. ${ }^{149}$

Pigs have recently been used as an alternative large animal model for studying C. trachomatis female genital tract infections caused by oculogenital serovars. The majority of genes expressed in major porcine FRT tissues and subsequently found to be expressed ubiquitously in human genital tissues are contained in cDNA libraries that have been constructed recently. ${ }^{150}$ specific pathogen free (SPF) outbred pigs (gilts) were evaluated for intravaginal infection $\left(1 \times 10^{8} \mathrm{IFU}\right)$ with C. trachomatis human serovar E genital isolate (strain 468). It was reported that human serovar E could ascend the genital tract of gilts, replicate in the cervical epithelium and uterine layers, and cause inflammation and pathology at the infection site. ${ }^{151}$

\section{VACCINES}

Immunity induced by natural chlamydial infection does not provide long-lasting protection and may contribute to pathology. A recent study involving DC pulsed with live or UV-irradiated EB reported that live EBs (but not UV-irradiated EBs) induced significant DC and neutrophil infiltration during infection, indicating that development of an anti-chlamydial response in vitro is greatly influenced by chlamydial viability. ${ }^{152}$ Table 1 summarizes recent chlamydial antigens, delivery systems, routes of immunization, and immune potentiators used for immunization against $C$. trachomatis genital tract infections. Delivery of vaccines is also summarized and includes systems (chemical, microbial-related, detergent-based, viral, cellular, DNA systems), mucosal (intranasal, intravaginal, rectal, transcutaneous), and systemic vaccination routes and also includes 


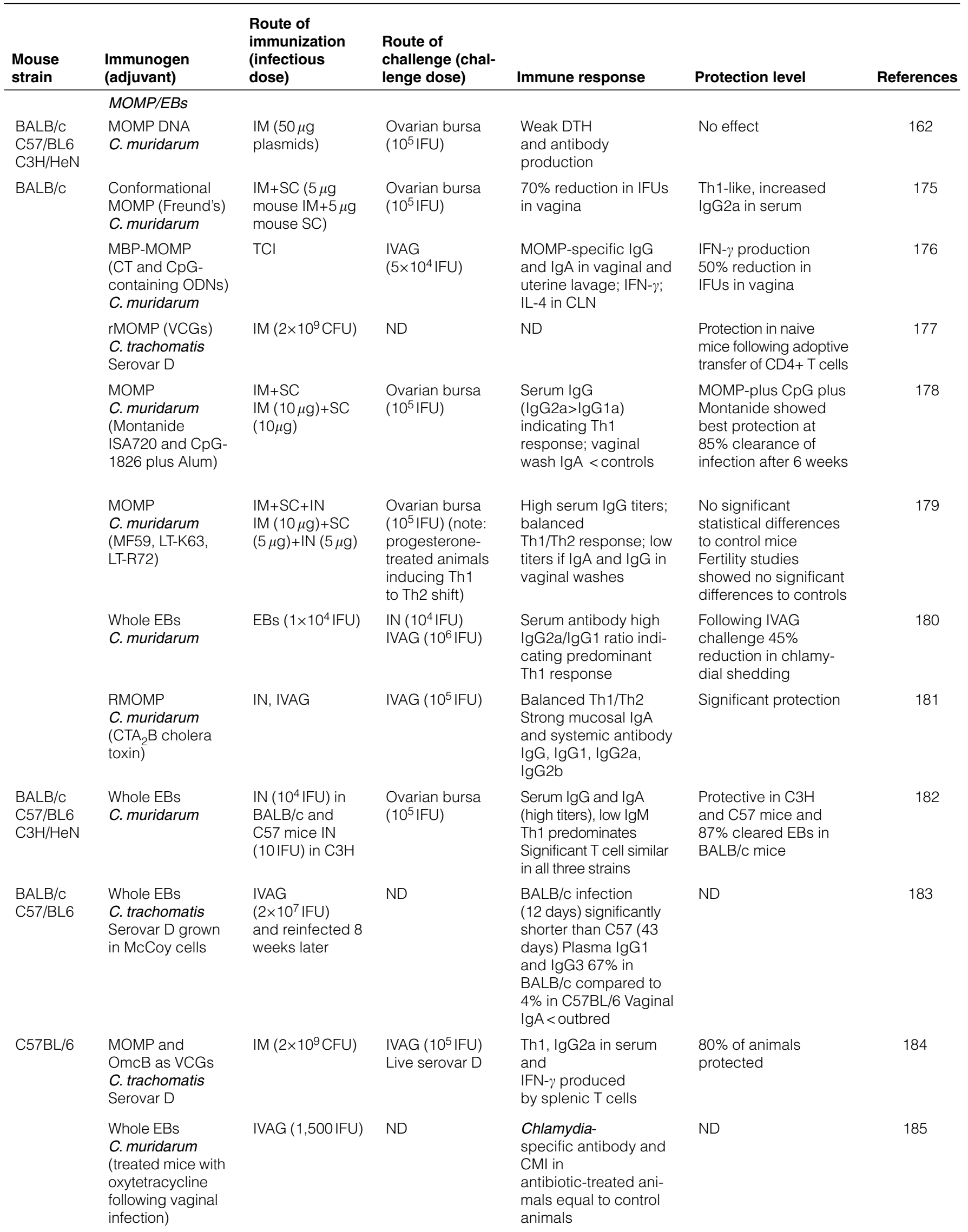




\begin{tabular}{|c|c|c|c|c|c|c|}
\hline $\begin{array}{l}\text { Mouse } \\
\text { strain }\end{array}$ & $\begin{array}{l}\text { Immunogen } \\
\text { (adjuvant) }\end{array}$ & $\begin{array}{l}\text { Route of } \\
\text { immunization } \\
\text { (infectious } \\
\text { dose) }\end{array}$ & $\begin{array}{l}\text { Route of } \\
\text { challenge } \\
\text { (challenge } \\
\text { dose) }\end{array}$ & Immune response & Protection level & References \\
\hline & $\begin{array}{l}\text { MOMP (immu- } \\
\text { nodominant T-cell } \\
\text { epitopes) As } \\
\text { recombinant } \\
\text { influenza (rIV-CT) } \\
\text { C. trachomatis } \\
\text { Serovar D }\end{array}$ & $\begin{array}{l}\text { IN }\left(10^{5} \text { PFU }\right. \\
\text { rIV-CT) }\end{array}$ & $\begin{array}{l}\text { IVAG }\left(10^{5} \mathrm{IFU}\right. \\
\text { C. trachomatis } \\
\text { serovar D) }\end{array}$ & $\begin{array}{l}\text { Strong Th1 response } \\
\text { against intact chlamy- } \\
\text { dial EBs High fre- } \\
\text { quency } \\
\text { of Chlamydia- } \\
\text { specific Th1 in genital } \\
\text { draining lymphoid tis- } \\
\text { sues }\end{array}$ & $\begin{array}{l}\text { Significant protective } \\
\text { immunity as seen by } \\
\text { reduced shedding of } \\
\text { Chlamydiae and rapid } \\
\text { clearance of infection }\end{array}$ & 187 \\
\hline $\mathrm{C} 3 \mathrm{H} / \mathrm{HeN}$ & $\begin{array}{l}\text { Whole EBs } \\
\text { C. muridarum and } \\
\text { C. trachomatis } \\
\text { Serovar } \mathrm{E}\left(1^{\circ}\right) \text { or } \\
\text { serovars } \mathrm{A}, \mathrm{E} \text {, or } \\
\mathrm{L} 2\left(2^{\circ}\right) \text { infection }\end{array}$ & $\begin{array}{l}\text { IVAG }\left(10^{4} \mathrm{IFU}\right) \\
\text { C. muridarum } \\
\text { (106 IFU) } \\
\text { C. trachomatis }\end{array}$ & IVAG & $\begin{array}{l}\text { Mice infected with } \\
\text { C. muridarum became } \\
\text { infertile with hydro- } \\
\text { salpinx formation } \\
\text { whether or not infected } \\
\text { previously with } \\
\text { C.trachomatis } \\
\text { Mice infected with } \\
\text { C. trachomatis } \\
\text { remained fertile unless } \\
\text { chalenged with homo- } \\
\text { logous Ctr serovar }\end{array}$ & $\begin{array}{l}\text { Homotypic challenge } \\
\text { leads to exacerbated } \\
\text { disease pathology }\end{array}$ & 132 \\
\hline $\begin{array}{l}\text { Outbred } \\
\text { CF-1 }\end{array}$ & $\begin{array}{l}\text { Whole EBs } \\
\text { C. trachomatis } \\
\text { Serovar D or H }\end{array}$ & $\begin{array}{l}\text { IVAG (1- } \\
3 \times 10^{7} \text { IFU) }\end{array}$ & ND & $\begin{array}{l}\text { Plasma and vaginal } \\
\text { secretions from sero- } \\
\text { var } \mathrm{D} \text {-infected mice } \\
\text { contained antibodies } \\
\text { to more antigens that } \\
\text { serovar } \mathrm{H}\end{array}$ & $\begin{array}{l}\text { Serovar D more } \\
\text { virulent (longer } \\
\text { duration of infection) } \\
\text { and immunogenic } \\
\text { (higher serum IgG and } \\
\text { vaginal IgA) Serovar D } \\
\text { showed homotypic and } \\
\text { heterotypic protection }\end{array}$ & 189 \\
\hline & $\begin{array}{l}\text { Non-MOMP } \\
\text { antigens }\end{array}$ & & & & & \\
\hline $\mathrm{BALB} / \mathrm{c}$ & $\begin{array}{l}\text { C. muridarum } \\
\text { TC0512 (putative } \\
\text { OMP), TC0757 } \\
\text { (conserved hypo- } \\
\text { thetical protein), } \\
\text { TCO439 (adher- } \\
\text { ence factor), } \\
\text { TCO767/768 hypo- } \\
\text { thetical protein) }\end{array}$ & $\begin{array}{l}\text { GG (intra- } \\
\text { abdominally) }\end{array}$ & $\begin{array}{l}\text { IVAG } \\
\left(5 \times 10^{4} \mathrm{IFU}\right)\end{array}$ & $\begin{array}{l}\text { Predominantly } \\
\text { Th2 (IL-4, IL-10); } \\
\text { IgG1>IgG2a }\end{array}$ & $\begin{array}{l}\text { Partial protection with } \\
\text { enhanced clearance } \\
\text { of infection }\end{array}$ & 169 \\
\hline
\end{tabular}




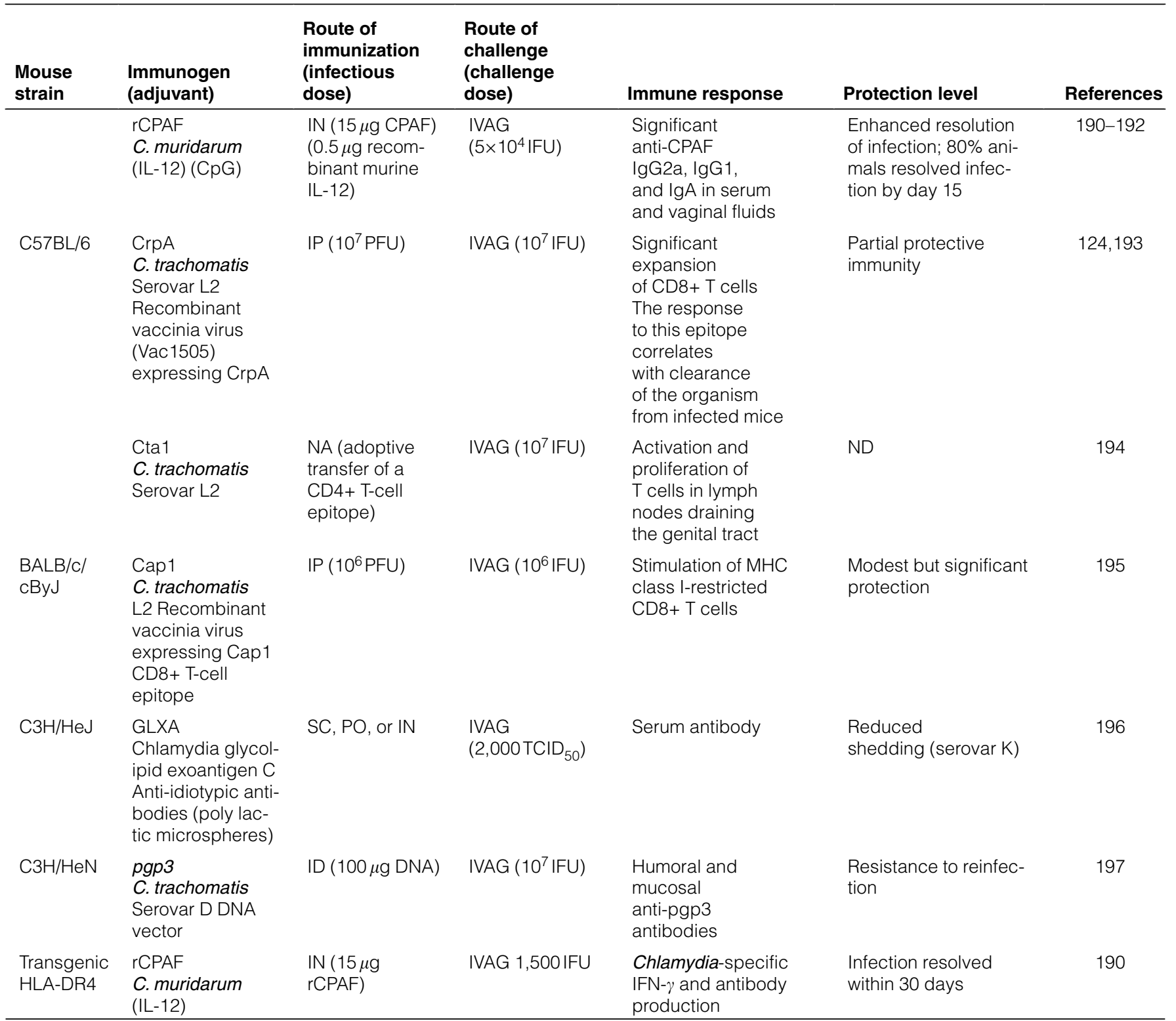

CLN, caudal and lumbar lymph nodes; Cap1, class I accessible protein; CFU, colony-forming unit; CMI, cell-mediated immune response; CPAF, chlamydial protease-like activity factor; CpG-1826, unmethylated bacterial CpG DNA (ODN no. 1826); CrpA, cysteine-rich protein A; Cta1, Chlamydia-specific T-cell antigen 1; DTH, delayed-type hypersensitivity; EBs, elementary bodies; FRT, female reproductive tract; GG, GeneGun; HSV-2, herpes simplex virus type 2; ID, intradermal; IFN, interferon; IFU, inclusion-forming unit; IL, interleukin; IM, intramuscular; IN, intranasal; IP, intraperitoneal; IVAG, intravaginal; LTK63, heat-labile Escherichia coli enterotoxin; LT-R72, a mutant of the heat-labile enterotoxin of Escherichia coli; MBP-MOMP, maltose binding protein fused to major outer membrane protein; MF59, an oil-in-water adjuvant emulsion containing squalene; MHC, major histocompatibility complex; Montanide ISA720, water-in-oil adjuvant Montanide ISA720 (ICC-1132/ISA 720); NA, not available; ND, not done; ODN, oligodeoxy nucleotide; OMP, outer membrane protein; PFU, plaqueforming unit; PO, per oral; PSac, peri-sacral; PV, peri-vaginal; rCPAF, recombinant CPAF; rMOMP, recombinant MOMP; rVCG, recombinant VCG; SC, subcutaneous; TCI, transcutaneous; $\mathrm{TCID}_{50}$, tissue culture infectious dose 50 ; Th, Thelper cell; VCG, Vibrio cholerae ghosts.

immune potentiators and mucosal adjuvants currently being trialled (Table $\mathbf{1}$ ).

Vaccine development against chlamydial infections has encompassed the use of inactivated, live whole organisms, subunit vaccines based on MOMP preparations, novel highly immunogenic components of chlamydial organisms that are other potential vaccine targets, recombinant protein and peptide vaccines, DNA vaccines to the more recent use of intranasal delivery of subunit vaccine using live attenuated influenza viruses as delivery vectors for chlamydial vaccines. ${ }^{153}$
In the 1950s and 1960s, early human vaccine studies focused on the use of inactivated or live whole organisms (reviewed in ref. ${ }^{129}$ ). In humans, whole organism vaccination against trachoma reduced disease and produced short-term protection in some individuals; ${ }^{154-156}$ however, reinfection exacerbated disease in others resulting from stimulation of enhanced delayed-type hypersensitivity reactions. The use of whole-cell organisms was essentially abandoned following these results; however, once a stable genetic system for transformation of Chlamydia is developed, it may be possible to produce a live 
attenuated vaccine provided any immunopathological damage is overcome.

Technology enabling the identification, isolation, and purification of antigenic determinants of Chlamydia has shifted the focus from a whole-cell vaccine approach to epitope, peptide, oligosaccharide, oligoglycopeptide, or subunit vaccines. The most promising vaccine candidate to date has been the $40 \mathrm{kDa}$ Omp- 1 antigen, also known as the MOMP. The results of MOMP-based vaccine studies have reported diverse degrees of immunogenicity and various levels of protective immunity ${ }^{106,109,157-168}$ (Table 1). The results with MOMP-based vaccines might imply either that MOMP alone is an inadequate vaccine candidate or that potentially better delivery systems and adjuvants are required for optimal protective effects using MOMP as candidate vaccine antigen.

Chlamydial genomics and proteomics are currently proving to be useful tools for the identification of novel immunogenic antigens $^{169-173}$ other than MOMP. Some of these antigens have also recently been trialled in vaccine studies with varying degrees of protection reported (see Table 1) and these may indeed be combined with chlamydial MOMP in future multicomponent vaccines.

Definitive infection control of chlamydial infections is highly likely to be achievable through a safe and efficacious vaccine in the near future. This will require identifying protective chlamydial antigens in animal models as well as identifying effective adjuvants and delivery systems that target subunit vaccines to immune inductive sites or secondary lymphoid tissues and that will be safe for use in humans.

Many studies have been focused on identifying protective chlamydial antigens as vaccine components and these include individual research groups and pharmaceutical companies. The strategies that have been used include identifying antigens that elicit antibodies that bind to the chlamydial cell surface, mucosal immunization of animals with a chlamydial protease-like activity factor, a protein secreted into the cytosol of Chlamydia-infected host cell (recombinant protein was administered to mice intranasally or intraperitoneally with CpG oligodeoxynucleotides), and our own novel approach using expression library immunization.

The antigens that have been identified include a pan-genus antigen, outer membrane protein epitopes, proteins found to be infection-specific, and a conserved surface-exposed polymorphic protein D. Using expression library immunization, our study identified six novel vaccine antigens that conferred protection against a genital tract challenge infection in mice and these included genes for hypothetical proteins and housekeeping genes, including a DNA gyrase subunit, TC0462, and the ATPdependent Clp protease, ATP-binding subunit ClpC, TC0559.

Vaccine strategies that are promising include mucosal delivery, which is also utilized for several vaccines, such as the cholera, typhoid, and original polio vaccines that are administered orally, and the live attenuated influenza $A$ and $B$ vaccine that is delivered intranasally. Mucosal delivery of a chlamydial vaccine has been shown to induce high levels of Chlamydia-specific IFN- $\gamma$ following immunization intranasally with live C. muridarum and resistance to reinfection with $C$. muridarum.

How close are we to a realistic vaccine? From our own investigations, we believe that we are only a couple of years away from clinical trials. We have already accumulated significant data using primarily our mouse genital tract model but using both C. muridarum and C. trachomatis strains. We have also discovered several novel protective antigens and aim to use a combination of these in our final vaccine product rather than simply using a single antigen as in most previous studies. We have also identified antigens that elicit strong antibody as well as Th1 type immune response characterized by the production of tumor necrosis factor- $\alpha$ and IFN- $\gamma$, both of which are crucial for chlamydial clearance in primary and secondary infections in humans.

\section{CONCLUSION AND FUTURE PROSPECTS}

Today, there is no vaccine for genital tract infections in humans caused by C. trachomatis.

Owing to the different life-cycle forms (EB, RB, persistent form) and serovar differences in surface proteins such as MOMP, a vaccine based on a single antigen is unlikely to generate protective immunity. Progress has, however, been made in our knowledge of humoral and cellular immunity to chlamydial infections (both protective vs. proinflammatory), as well as in the identification of potential vaccine candidate antigens other than MOMP that could be incorporated into a subunit vaccine while avoiding components that mediate immunopathological damage. Globally, the severity and economic impact of genital tract diseases in humans caused by $C$. trachomatis necessitates the development of an affordable efficacious prophylactic vaccine to control infections. The challenges in developing such a vaccine include difficulty in preparing a $100 \%$ safe and effective product, the increasingly high costs of testing (identified as $\$ 802$ million in 2000 (ref. 174)), and also the consideration that end users of the vaccine have to be motivated by the risk of an infection and disease that is only a potential future threat to their health and well-being. An ideal vaccine must include heterotypic cross-protection against the many serotypes of $C$. trachomatis as well as one that can achieve sterilizing immunity in the FRT. However, a vaccine that prevented ascending infection and reduced shedding would have a major economic benefit and there are many papers modeling this scenario. The natural reproductive cycle and its effects on the physiology and immunity in the FRT may make this latter goal difficult to achieve; however, mucosally administered vaccines are capable of inducing long-lasting immune responses in the genital tract. A more feasible goal of a prophylactic chlamydial vaccine might be to protect women from disease rather than infection, and this might well be achieved by developing vaccines both for men and women. This is a future prospect that increases our current optimism for the development of an efficacious vaccine against sexually transmitted diseases.

\section{ACKNOWLEDGMENTS}

We acknowledge funding from the Australian National Health and Medical Research Council.

\section{DISCLOSURE}

The authors declared no conflict of interest.

(C) 2008 Society for Mucosal Immunology 


\section{REFERENCES}

1. WHO. Global Prevalence and Incidence of Selected Curable Sexually Transmitted Infections: Overview and Estimates. World Health Organization, Geneva, Switzerland, 2001.

2. Blandford, J.M. \& Gift, T.L. Productivity losses attributable to untreated chlamydial infection and associated pelvic inflammatory disease in reproductive-aged women. Sex. Transm. Dis. 33, S117-S121 (2006).

3. CDC. Sexually Transmitted Disease Surveillance 2005 Supplement, Chlamydia Prevalence Monitoring Project Annual Report 2005. US Department of Health and Human Services, Centers for Disease Control and Prevention, Atlanta, GA, December 2006.

4. Stamm, W.E. Chlamydia trachomatis infections: progress and problems. J. Infect. Dis. 179 (Suppl 2), S380-S383 (1999).

5. Pimenta, J.M. et al. Opportunistic screening for genital chlamydial infection II: prevalence among healthcare attendees, outcome and evaluation of positive cases. Sex. Transm. Infect. 79, 22-27 (2003).

6. Weinstock, H., Berman, S. \& Cates, W. Jr. Sexually transmitted diseases among American youth: incidence and prevalence estimates, 2000 Perspect. Sex. Reprod. Health 36, 6-10 (2004).

7. Abdel Rahman, Y.M. \& Belland, R.J. The chlamydial developmental cycle. FEMS Microbiol. Rev. 29, 949-959 (2005).

8. Stephens, R.S., Poteralski, J.M. \& Olinger, L. Interaction of Chlamydia trachomatis with mammalian cell is independent of host cell surface heparan sulphate glycosaminoglycans. Infect. Immun. 74, 1795-1799 (2006).

9. Hackstadt, T. Cell biology. In Chlamydia: Intracellular Biology, Pathogenesis and Immunity (Stephens, R.S., ed) 101-139 (ASM Press, Washington, DC, 1999).

10. Van Ooij, C., Apodaca, G. \& Engel, J.N. Characterization of the Chlamydia trachomatis vacuole and its interaction with the host endocytic pathway in HeLa cells. Infect. Immun. 65, 758-766 (1997).

11. Wyrick, P.B. Intracellular survival by Chlamydia. Cell. Microbiol. 2, 275-282 (2000)

12. Davis, C. \& Raulston, J.E. Protein disulfide isomerase, a component of the estrogen receptor complex, is associated with Chlamydia trachomatis serovar E attached to human endometrial epithelial cells. Infect. Immun. 70, 3413-3418 (2002).

13. Kutlin, A., Roblin, P.M. \& Hammerschlag, M.R. In vitro activities of azithromycin and ofloxacin against Chlamydia pneumoniae in a continuous-infection model. Antimicrob. Agents Chemother. 43, 2268-2272 (1999).

14. Hanada, H., Ikeda-Dantsuji, Y. \& Naito, M. Infection of human fibroblastlike synovial cells with Chlamydia trachomatis results in persistent infection and interleukin-6 production. Microb. Pathog. 34, 57-63 (2003).

15. Coles, A.M. et al. Low-nutrient induction of abnormal chlamydial development: a novel component of chlamydial pathogenesis? FEMS Microbiol. Lett. 106, 193-200 (1993).

16. Hogan, R.J. et al. Chlamydial persistence: beyond the biphasic paradigm. Infect. Immun. 72, 1843-1855 (2004).

17. Patton, D.L. et al. Detection of Chlamydia trachomatis in fallopian tube tissue in women with postinfectious tubal infertility. Am. J. Obstet. Gynecol. 171, 95-101 (1994).

18. Holland, S.M. et al. Demonstration of chlamydial RNA and DNA during a culture-negative state. Infect. Immun. 60, 2040-2047 (1992).

19. Nanagara, R. et al. Alteration of Chlamydia trachomatis biologic behaviour in synovial membranes: suppression of surface antigen production in reactive arthritis and Reiter's syndrome. Athritis Rheum. 38, 1410-1417 (1995)

20. Dean, D., Suchland, R.J. \& Stamm, W.E. Evidence for long-term cervical persistence of Chlamydia trachomatis by omp1 genotyping. J. Infect. Dis. 182, 909-916 (2000).

21. Bragina, E.Y., Gomberg, M.A. \& Dmitriev, G.A. Electron microscopic evidence of persistent chlamydial infection following treatment. J. Eur. Acad. Dermatol. Venereol. 15, 405-409 (2001).

22. Bazala, E. \& Renda, J. Latent chlamydial infections: the probable cause of a wide spectrum of human diseases. Med. Hypotheses $65,578-584$ (2005).

23. Mpiga, P. \& Ravaoarioro, M. Chlamydia trachomatis persistence: an update. Microbiol. Res. 161, 9-19 (2006).

24. Molano, M. et al. Combination of PCR targeting the VD2 of omp1 and reverse line blot analysis for typing of urogenital Chlamydia trachomatis serovars in cervical scrape specimens. J. Clin. Microbiol. 42 2935-2939 (2004)

25. Xiong, L. et al. Use of PCR and reverse line blot hybridisation assay for simultaneous detection and serovar identification of Chlamydia trachomatis. J. Clin. Microbiol. 44, 1413-1418 (2006).

26. Yang, C.L., Maclean, I. \& Brunham, R.C. DNA sequence polymorphism of the Chlamydia trachomatis omp1 gene. J. Infect. Dis. 168, 1225-1230 (1993)

27. Dean, D., Oudens, E., Bolan, G., Padian, N. \& Schachter, J. Major outer membrane protein variants of Chlamydia trachomatis are associated with severe upper genital tract infections and histopathology in San Francisco. J. Infect. Dis. 172, 1013-1022 (1995).

28. Rodriguez, P. et al. Evaluation of molecular typing for epidemiological study of Chlamydia trachomatis genital infections. J. Clin. Microbiol. 31, 2238-2240 (1993).

29. Kuo, C.-C. et al. Immunotypes of Chlamydia trachomatis isolates in Seattle, Washington. Infect. Immun. 41, 865-868 (1983).

30. Spaargaren, J. et al. Analysis of Chlamydia trachomatis serovar distribution changes in the Netherlands (1986-2002). Sex. Transm. Infect. 80, 151-156 (2004)

31. Chungue, E. et al. Immunotypes of Chlamydia trachomatis isolated from genital tract specimens in Tahiti. Eur. J. Clin. Mcrobiol. Infect. Dis. 13, 436-438 (1994).

32. Millman, K. et al. Population-based genetic and evolutionary analysis of Chlamydia trachomatis urogenital strain variation in the United States. J. Bacteriol. 186, 2457-2465 (2004).

33. Barnes, R.C., Rompala, A.M. \& Srtamm, W.E. Comparison of Chlamydia trachomatis serovars causing rectal and cervical infections. J. Infect. Dis. 156, 953-958 (1987).

34. Gomes, J.P. et al. Correlating Chlamydia trachomatis infectious load with urogenital ecological success and disease pathogenesis. Microbes Infect. 8, 16-26 (2006)

35. Lan, J. et al. Prevalence and serovar distribution of asymptomatic cervical Chlamydia trachomatis infections as determined by highly sensitive PCR. J. Clin. Microbiol. 33, 3194-3197 (1995).

36. Workowski, K.A. et al. Association of genital infection with specific Chlamydia trachomatis serovars and race. J. Infect. Dis. 166 1445-1449 (1992)

37. Geisler, W.M., Suchland, R.J. \& Stamm, W.E. Association of Chlamydia trachomatis serovar la infection with black race in a sexually transmitted disease clinic patient population in Birmingham, Alabama. Sex. Transm. Dis. 33, 621-624 (2006).

38. Gomes, J.P. et al. Correlating Chlamydia trachomatis infectious load with urogenital ecological success and disease pathogenesis. Microbes Infect. 8, 16-26 (2006).

39. Geisler, W.M. Approaches to the management of uncomplicated genital Chlamydia trachomatis infections. Expert Rev. Anti Infect. Ther. 2 , 771-785 (2004).

40. Stamm, W.E. Chlamydia trachomatis - the persistent pathogen. Sex. Transm. Dis. 28, 684-689 (2001).

41. Fortenberry, J.D. et al. Subsequent sexually transmitted infections among adolescent women with genital infection due to Chlamydia trachomatis,Neisseria gonorrhoeae, or Trichomonas vaginalis. Sex. Transm. Dis. 26, 26-32 (1999).

42. Wyrick, P.B. \& Knight, S.T. Pre-exposure of infected human endometrial epithelial cells to penicillin in vitro renders Chlamydia trachomatis refractory to azithromycin. J. Antimicrob. Chemother. 54, 79-85 (2004)

43. Horner, P. The case for further treatment studies of uncomplicated genital Chlamydia trachomatis infection. Sex. Transm. Infect. 82, 340-343 (2006).

44. Weisenfeld, H.C. et al. Association between elevated neutrophil defensin level and endometritis. J. Infect. Dis. 186, 792-797 (2002).

45. Koskela, P. et al. Chlamydia trachomatis infection as a risk factor for invasive cervical cancer. Int. J. Cancer 85, 35-39 (2000).

46. Samoff, E. et al. Association of Chlamydia trachomatis with persistence of high-risk types of human papillomavirus in a cohort of female adolescents. Am. J. Epidemiol. 162, 668-675 (2005).

47. Plummer, F.A. et al. Co-factors in male-female sexual transmission of human immunodeficiency virus type 1. J. Infect. Dis. 163, 233-239 (1991). 
48. Brunham, R.C. \& Rey-Ladino, J. Immunology of Chlamydia infection: implications for a Chlamydia trachomatis vaccine. Nat. Rev. Immunol. 5 , 149-161 (2005).

49. Ramsey, K.H. et al. Expression of matrix metalloproteinases subsequent to urogenital Chlamydia muridarum infection of mice. Infect. Immun. 73, 6962-6973 (2005).

50. Shah, A.A. et al. Histopathologic changes related to fibrotic oviduct occlusion after genital tract infection of mice with Chlamydia muridarum. Sex. Transm. Dis. 32, 49-56 (2005).

51. Imtiaz, M.T. et al. Inhibition of matrix metalloproteinases protects mice from ascending infection and chronic disease manifestations resulting from urogenital Chlamydia muridarum infection. Infect. Immun. 74, 5513-5521 (2006).

52. Bachmaier, K. \& Penninger, J.M. Chlamydia and antigenic mimicry. Curr. Top. Microbiol. Immunol. 296, 153-163 (2005).

53. Yi, Y., Yang, X. \& Brunham, R.C. Autoimmunity to heat shock protein 60 and antigen-specific production of interleukin-10. Infect. Immun. 65, 1669-1674 (1997).

54. Allen, J.E. \& Stephens, R.S. Identification by sequence analysis of 2-site posttranslational processing of the cysteine-rich outer-membrane protein-2 of Chlamydia trachomatis serovar L2. J. Bacteriol. 171, 285-291 (1989).

55. Kinnunen, A. et al. Chlamydia trachomatis reactive T lymphocytes from upper genital tract tissue specimens. Hum. Reprod. 15, 1484-1489 (2000).

56. Kinnunen, A. et al. Chlamydial heat shock protein 60-specific T cells in inflamed salpingeal tissue. Fertil. Steril. 77, 162-166 (2002).

57. Kinnunen, A. et al. Chlamydia trachomatis heat shock protein-60 induced interferon-gamma and interleukin-10 production in infertile women. Clin. Exp. Immunol. 131, 299-303 (2003).

58. Tiitinen, A. et al. Chlamydia trachomatis and chlamydial heat-shock protein 60-specific antibody and cell-mediated responses predict tubal factor infertility. Hum. Reprod. 21, 1533-1538 (2006).

59. Larue, R.W., Dill, B.D., Gilés, D.K., Whittimore, J.D. \& Raulston, J.E. Chlamydial Hsp60-2 is iron-responsive in Chlamydia trachomatis serovar E-infected human endometrial epithelial cells in vitro. Infect. Immun. 75, 2374-2380 (2007).

60. LaVerda, D. et al. Seroreactivity to Chlamydia trachomatis Hsp10 correlates with severity of human genital tract disease. Infect. Immun. 68, 303-309 (2000).

61. Betsou, F. et al. Cross-reactivity between Chlamydia trachomatis heat shock protein 10 and early pregnancy factor. Clin. Diagn. Lab. Immunol. 10, 446-450 (2003).

62. den Hartog, J.E. et al. Do host genetic traits in the bacterial sensing system play a role in the development of Chlamydia trachomatisassociated tubal pathology in subfertile women? BMC Infect. Dis. 6, 122 (2006).

63. Wira, C.R. et al. Innate and adaptive immunity in female genital tract: cellular responses and interactions. Immunol. Rev. 206, 306-335 (2005).

64. Yeaman, G.R. et al. CD8+ T cells in human uterine endometrial lymphoid aggregates: evidence for accumulation of cells by trafficking. Immunology 102, 434-440 (2001).

65. Mestecky, J., Moldoveanu, Z. \& Russell, M. Immunologic uniqueness of the genital tract: challenge for vaccine development. Am. J. Reprod. Immunol. 53, 208-214 (2005).

66. Medzhitov, R. \& Janeway, C.A. Jr. Toll receptor family and microbial recognition. Trends Microbiol. 8, 452-456 (2000).

67. Wira, C.R., Grant-Tschudy, K.S. \& Crane-Godreau, M.A. Epithelial cells in the female reproductive tract: a central role as sentinels of immune protection. Am. J. Reprod. Immunol. 53, 65-76 (2005).

68. Severin, J.A. \& Ossewaarde, J.M. Innate immunity in defense against Chlamydia trachomatis infections. Drugs Today (Barc) 42 (Suppl. A), 75-81 (2006).

69. Dessus-Babus, S. et al. Differences in innate immune responses (in vitro) to HeLa cells infected with nondisseminating serovar $E$ and disseminating serovar L2 of Chlamydia trachomatis. Infect. Immun. 70, 3234-3248 (2002).

70. Entrican, G. et al. Induction of inflammatory host immune responses by organisms belonging to the genera Chlamydia/Chlamydophila. Vet. Immunol. Immunopathol. 100, 179-186 (2004).
71. Rasmussen, S.J. et al. Secretion of proinflammatory cytokines by epithelial cells in response to Chlamydia infection suggests a central role for epithelial cells in chlamydial pathogenesis. J. Clin. Invest. 99, 77-87 (1997).

72. Vabulas, R.M. et al. Endocytosed HSP60s use Toll-like receptor 2 (TLR2) and TLR4 to activate the Toll/interleukin-1 receptor signaling pathway in innate immune cells. J. Biol. Chem. 276, 31332-31339 (2001).

73. Welter-Stahl, L. et al. Stimulation of the cytosolic receptor for peptidoglycan, Nod1, by infection with Chlamydia trachomatis or Chlamydia muridarum. Cell. Microbiol. 8, 1047-1057 (2006).

74. Schnare, M. et al. Toll-like receptors control activation of adaptive immune responses. Nat. Immunol. 2, 947-950 (2001).

75. Derbigny, W.A., Kerr, M.S. \& Johnson, R.M. Pattern recognition molecules activated by Chlamydia muridarum infection of cloned murine oviduct epithelial cell lines. J. Immunol. 175, 6065-6075 (2005).

76. Darville, T. et al. Toll-like receptor-2, but not Toll-like receptor-4, is essential for development of oviduct pathology in chlamydial genital tract infection. J. Immunol. 171, 6187-6197 (2003).

77. Nagarajan, U.M. et al. Chlamydia trachomatis induces expression of IFN-gamma-inducible protein 10 and IFN-beta independent of TLR2 and TLR4, but largely dependent on MyD88I. J. Immunol. 175, 450-460 (2005).

78. Imtiaz, M.T. et al. Outcome of urogenital infection with Chlamydia muridarum in CD14 gene knockout mice. BMC Infect. Dis. 6, 144-149 (2006).

79. O'Connell, C.M. et al. Localization of TLR2 and MyD88 to Chlamydia trachomatis inclusions. Evidence for signaling by intracellular TLR2 during infection with an obligate intracellular pathogen. J. Biol. Chem. 281, 1652-1659 (2006).

80. Derbigny, W.A. et al. Chlamydia muridarum infection elicits a beta interferon response in murine oviduct epithelial cells dependent on interferon regulatory factor 3 and TRIF. Infect. Immun. 75, 1280-1290 (2007).

81. Hook, C.E. et al. Effects of Chlamydia trachomatis infection on the expression of natural killer (NK) cell ligands and susceptibility to NK cell Iysis. Clin. Exp. Immunol. 138, 54-60 (2004).

82. Hook, C.E., Matyszak, M.K. \& Gaston, J.S. Infection of epithelial and dendritic cells by Chlamydia trachomatis results in IL-18 and IL-12 production, leading to interferon-gamma production by human natural killer cells. FEMS Immunol. Med. Microbiol. 45, 113-120 (2005).

83. Shemer-Avni, Y., Wallach, D. \& Sarov, I. Reversion of the antichlamydial effect of tumor necrosis factor by tryptophan and antibodies to beta interferon. Infect. Immun. 57, 3484-3490 (1989).

84. Decker, T., Muller, M. \& Stockinger, S. The yin and yang of type I interferon activity in bacterial infection. Nat. Rev. Immunol. 5, 675-687 (2005).

85. Reis e Sousa, C. Activation of dendritic cells: translating innate into adaptive immunity. Curr. Opin. Immunol. 16, 21-25 (2004).

86. Hanenberg, B., Kendall, D., Amerongen, H.M., Apter, F.M. Kraehenbuhl, J.P. \& Neutra, M.R. Induction of specific immunoglobulin $A$ in the small intestine, colon-rectum, and vagina measured by a new method for collection of secretions from local mucosal surfaces. Infect. Immun. 62, 15-23 (1994).

87. Kozlowski, P.A. et al. Mucosal vaccination strategies for women. J. Infect. Dis. 179 (Suppl 3), S493-S498 (1999).

88. Gould, D.S., Ploegh, H.L. \& Schust, D.J. Murine female reproductive tract intraepithelial lymphocytes display selection characteristics distinct from both peripheral and other mucosal T cells. J. Reprod. Immunol. 52, 85-99 (2001).

89. Kelly, K.A. et al. Differential regulation of CD4 lymphocyte recruitment between the upper and lower regions of the genital tract during Chlamydia trachomatis infection. Infect. Immun. 68, 1519-1528 (2000).

90. Su, H. et al. Chlamydia trachomatis genital tract infection of antibodydeficient gene knockout mice. Infect. Immun. 65, 1993-1999 (1997).

91. Hawkins, R.A., Rank, R.G. \& Kelly, K.A. A Chlamydia trachomatisspecific Th2 clone does not provide protection against a genital infection and displays reduced trafficking to the infected genital mucosa. Infect. Immun. 70, 5132-5139 (2002).

92. Williams, D.M. et al. Humoral and cellular immunity in secondary infection due to murine Chlamydia trachomatis. Infect. Immun. 65, 2876-2882 (1997). 
93. Yang, X. \& Brunham, R.C. Gene knockout B cell-deficient mice demonstrate that $B$ cells play an important role in the initiation of $T$ cell responses to Chlamydia trachomatis (mouse pneumonitis) lung infection. J. Immunol. 161, 1439-1446 (1998).

94. Johasson, M., Ward, M. \& Lycke, N. B-cell deficient mice develop complete immune protection against genital tract infection with Chlamydia trachomatis. Immunology 92, 422-428 (1997).

95. Moore, T. et al. Fc receptor-mediated antibody regulation of $\mathrm{T}$ cell immunity against intracellular pathogens. J. Infect. Dis. 188, 617-624 (2003).

96. Morrison, S.G. \& Morrison, R.P. A predominant role for antibody in acquired immunity to chlamydial genital tract reinfection. J. Immunol. 175, 7536-7542 (2005).

97. Morrison, S.G. \& Morrison, R.P. Humoral immunity to Chlamydia muridarum genital tract infection. In Proceedings of the 11th International Symposium on Human Chlamydial Infection, (Niagaraon-the-Lake, ON, Canada, 2006 ).

98. Hickey, D.K. et al. Intranasal immunization with C. muridarum major outer membrane protein (MOMP) and cholera toxin elicits local production of neutralising IgA in the prostate. Vaccine 22, 4306-4315 (2004).

99. Igietseme, J.U. et al. Route of infection that induces a high intensity of gamma interferon-secreting $T$ cells in the genital tract produces optimal protection against Chlamydia trachomatis infection in mice. Infect. Immun. 66, 4030-4035 (1998).

100. Pal, S., Peterson, E.M. \& De la Maza, L.M. Intranasal immunization induces long-term protection in mice against a Chlamydia trachomatis genital challenge. Infect. Immun. 64, 5341-5348 (1996).

101. Pal, S. et al. Protection against infertility in a BALB/c mouse salpingitis model by intranasal immunization with the mouse pneumonitis biovar of Chlamydia trachomatis. Infect. Immun. 62, 3354-3362 (1994).

102. Pal, S. et al. Immunization with an acellular vaccine consisting of the outer membrane complex of Chlamydia trachomatis induces protection against a genital challenge. Infect. Immun. 65, 3361-3369 (1997).

103. Zhang, D. et al. Immunity to Chlamydia trachomatis mouse pneumonitis induced by vaccination with live organisms correlates with early granulocyte-macrophage colony-stimulating factor and interleukin-12 production and with dendritic cell-like maturation. Infect. Immun. 67, 1606-1613 (1999).

104. Brunham, R.C. \& Zhang, D. Transgene as vaccine for chlamydia Am. Heart J. 138 (5 Part 2), S519-S522 (1999).

105. Moore, T. et al. Fc receptor regulation of protective immunity against Chlamydia trachomatis. Immunology 105, 213-221 (2002).

106. Igietseme, J.U. et al. Developing effective delivery systems for Chlamydia vaccines. Curr. Opin. Mol. Ther. 6, 182-194 (2004).

107. Kelly, K.A. T-lymphocyte trafficking to the female reproductive tract mucosae. In Chlamydia: Genomics and Pathogenesis (Bavoil, P.M \& Wyrick, P.B., eds) 413-435 (Horizon Bioscience, Norfolk, UK, 2006).

108. Morrison, R.P., Feilzer, K. \& Tumas, D.B. Gene knockout mice establish a primary protective role for major histocompatibility complex class IIrestricted responses in Chlamydia trachomatis genital tract infection. Infect. Immun. 63, 4661-4668 (1995).

109. Su, H. \& Caldwell, H.D. CD4+ T cells play a significant role in adoptive immunity to Chlamydia trachomatis infection of the mouse genital tract. Infect. Immun. 63, 3302-3308 (1995).

110. Rank, R.G. \& Sanders, M.M. Pathogenesis of endometritis and salpingitis in a guinea pig model of chlamydial genital infection. Am. J. Pathol. 140, 927-936 (1992)

111. Zhong, G., Fan, T. \& Liu, L. Chlamydia inhibits interferon gammainducible major histocompatibility complex class II expression by degradation of upstream stimulatory factor 1. J. Exp. Med. 189, 1931-1938 (1999)

112. Igietseme, J.U. The molecular mechanism of T-cell control of Chlamydia in mice: role of nitric oxide. Immunology 87, 1-8 (1996).

113. Loomis, W.P. \& Starnbach, M.N. T cell responses to Chlamydia trachomatis. Curr. Opin. Microbiol. 5, 87-91 (2002).

114. Pudney, J., Quayle, A.J. \& Anderson, D.J. Immunological microenvironments in the human vagina and cervix: mediators of cellular immunity are concentrated in the cervical transformation zone. Biol. Reprod. 73, 1253-1263 (2005).
115. Parr, M.B. \& Parr, E.L. Antigen recognition in the female reproductive tract: I. Uptake of intraluminal protein tracers in the mouse vagina. J. Reprod. Immunol. 17, 101-114 (1990).

116. Miller, C.J., McChesney, M. \& Moore, P.F. Langerhans cells, macrophages and lymphocyte subsets in the cervix and vagina of rhesus macaques. Lab. Invest. 67, 628-634 (1992).

117. Shaw, J.H. et al. Expression of genes encoding Th1 cell-activating cytokines and lymphoid homing chemokines by chlamydia-pulsed dendritic cells correlates with protective immunizing efficacy. Infect. Immun. 69, 4667-4672 (2001).

118. Matyszak, M.K. \& Gaston, J.S. Chlamydia trachomatis-specific human CD8+ T cells show two patterns of antigen recognition. Infect. Immun. 72, 4357-4367 (2004)

119. Rey-Ladino, J. et al. A live and inactivated Chlamydia trachomatis mouse pneumonitis strain induces the maturation of dendritic cells that are phenotypically and immunologically distinct. Infect. Immun. 73, 1568-1577 (2005)

120. Zaharik, M.L. et al. Genetic profiling of dendritic cells exposed to live- or ultraviolet-irradiated Chlamydia muridarum reveals marked differences in CXC chemokine profiles. Immunology 120, 160-172 (2006).

121. Reddy, B.S. et al. Cytokine expression pattern in the genital tract of Chlamydia trachomatis positive infertile women -implication for T-cell responses. Clin. Exp. Immunol. 137, 552-558 (2004).

122. Wang, C. et al. Interleukin (IL)-2 and IL-12 responses to Chlamydia trachomatis infection in adolescents. Clin. Exp. Immunol. 142, 548-554 (2005).

123. Roan, N.R. et al. Monitoring the $T$ cell response to genital tract infection. Proc. Natl. Acad. Sci. USA 103, 12069-12074 (2006).

124. Roan, N.R. \& Starnbach, M.N. Antigen-specific CD8+ T cells respond to Chlamydia trachomatis in the genital mucosa. J. Immunol. 177, 7974-7979 (2006)

125. Rank, R.G. The role of CD4 T cell in the host response to Chlamydia. In Chlamydia: Genomics and Pathogenesis (Bavoil, P.M. \& Wyrick, P.B., eds) 365-381 (Horizon Bioscience, Norfolk, UK, 2006).

126. Lyons, J. An integrated approach to the study of Chlamydia trachomatis infection of the female genital tract. Drugs Today 42 (Suppl A), 83-97 (2006).

127. Vanrompay, D., Lyons, J.M. \& Morre, S.A. Animal models for the study of Chlamydia trachomatis infections in the female genital infection. Dugs Today 42 (Suppl A), 55-63 (2006).

128. Morrison, R.P. \& Caldwell, H.D. Immunity to murine chlamydial genital infection. Infect. Immun. 70, 2741-2751 (2002).

129. Rank, R.G. Models of immunity. In Chlamydia: Intracellular Biology, Pathogenesis and Immunity (Stephens, R.S., ed) 239-295 (American Society for Microbiology, Washington, DC, 1999).

130. Tuffrey, M. et al. Genetic susceptibility to chlamydial salpingitis and subsequent infertility in mice. J. Reprod. Fertil. 95, 31-38 (1992).

131. Darville, T. et al. Mouse strain-dependent variation in the course and outcome of chlamydial genital tract infection is associated with differences in host response. Infect. Immun. 65, 3065-3073 (1997).

132. Ramsey, K.H., DeWolfe, J.L. \& Salyer, R.D. Disease outcome subsequent to primary and secondary urogenital infection with murine or human biovars of Chlamydia trachomatis. Infect. Immun. 68, 7186-7189 (2000)

133. Barron, A.L., White, H.J., Rank, R.G., Soloff, B.L. \& Moses, E.B. A new animal model for the study of Chlamydia trachomatis genital infections: infection of mice with the agent of mouse pneumonitis. J. Infect. Dis. 143, 63-66 (1981).

134. Morrison, S.G. \& Morrison, R.P. In situ analysis of the evolution of the primary immune response in murine Chlamydia trachomatis genital tract infection. Infect. Immun. 68, 2870-2879 (2000).

135. Morre, S.A. et al. Prevalence and serovar distribution of asymptomatic cervical Chlamydia trachomatis infections as determined by highly sensitive PCR. J. Clin. Microbiol. 38, 2292-2296 (2000).

136. Roshick, C. et al. Comparison of gamma interferon-mediated antichlamydial defense mechanisms in human and mouse cells. Infect. Immun. 74, 225-238 (2006).

137. Nelson, D.E. et al. Chlamydial IFN-gamma immune evasion is linked to host infection tropism. Proc. Natl. Acad. Sci. USA 102, 10658-10663 (2005). 
138. Yasui, H. et al. Interferon enhances tryptophan metabolism by inducing pulmonary indoleamine 2,3-dioxygenase: its possible occurrence in cancer patients. Proc. Natl. Acad. Sci. USA 83, 6622-6626 (1986).

139. Thomas, S.M. et al. IFN-gamma-mediated antimicrobial response. Indoleamine 2,3-dioxygenase-deficient mutant host cells no longer inhibit intracellular Chlamydia spp. or Toxoplasma growth. J. Immunol. 150, 5529-5534 (1993).

140. McClarty, G., Caldwell, H.D. \& Nelson, D.E. Chlamydial interferon gamma immune evasion influences infection tropism. Curr. Opin. Microbiol. 10, 47-51 (2007).

141. Mount, D.T., Bigazzi, P. \& Barron, A.L. Experimental genital infection of male guinea pigs with the agent of guinea pig inclusion conjunctivitis and transmission to females. Infect. Immun. 8, 925-930 (1973).

142. Rank, R.G. et al. Characterization of chlamydial genital infection resulting from sexual transmission from male to female guinea pigs and determination of infectious dose. Infect. Immun. 71, 6148-6154 (2003).

143. Bannantine, J.P. \& Rockey, D.D. Use of primate model system to identify Chlamydia trachomatis protein antigens recognized uniquely in the context of infection. Microbiology 145 (Part 8), 2077-2085 (1999).

144. Van Voorhis, W.C. et al. Repeated Chlamydia trachomatis infection of Macaca nemestrina fallopian tubes produces a Th1-like cytokine response associated with fibrosis and scarring. Infect. Immun. 65, 2175-2182 (1997).

145. Patton, D.L. et al. Effects of doxycycline and antiinflammatory agents on experimentally induced chlamydial upper genital tract infection in female macaques. J. Infect. Dis. 175, 648-654 (1997).

146. Lichtenwalner, A.B. et al. Evidence of genetic susceptibility to Chlamydia trachomatis-induced pelvic inflammatory disease in the pig-tailed macaque. Infect. Immun. 65, 2250-2253 (1997).

147. Peeling, R.W. et al. Antibody response to the chlamydial heat-shock protein 60 in an experimental model of chronic pelvic inflammatory disease in monkeys (Macaca nemestrina). J. Infect. Dis. 180, 774-779 (1999).

148. Patton, D.L., Sweeney, Y.T. \& Stamm, W.E. Significant reduction in inflammatory response in the macaque model of chlamydial pelvic inflammatory disease with azithromycin treatment. J. Infect. Dis. 192, 129-135 (2005).

149. Bannantine, J.P. \& Rockey, D.D. Use of primate model system to identify Chlamydia trachomatis protein antigens recognized uniquely in the context of infection. Microbiology 145 (Part 8), 2077-2085 (1999).

150. Tuggle, C.K. et al. EST-based gene discovery in pig: virtual expression patterns and comparative mapping to human. Mamm. Genome 14, 565-579 (2003).

151. Vanrompay, D. et al. Specific-pathogen-free pigs as an animal model for studying Chlamydia trachomatis genital infection. Infect. Immun. 73, 8317-8321 (2005).

152. Zaharik, M.L. et al. Genetic profiling of dendritic cells exposed to live- or ultraviolet-irradiated Chlamydia muridarum reveals marked differences in CXC chemokine profiles. Immunology 120, 160-172 (2007).

153. He, Q. et al. Live-attenuated influenza viruses as delivery vectors for Chlamydia vaccines. Immunology 23, 1-10 (2007).

154. Collier, L.H. \& Blyth, W.A. Immunogenicity of experimental trachoma vaccines in baboons. III. Experiments with inactivated vaccines. J. Hyg. (Cambridge) 65, 97-107 (1967).

155. Wang, S.P., Grayston, J.T. \& Alexander, E.R. Trachoma vaccine studies in monkeys. Am. J. Ophthalmol. 63, 1615-1630 (1967).

156. Woolridge, R.L. et al. Long-term follow-up of the initial (1959-1960) trachoma vaccine field trail on Taiwan. Am. J. Ophthalmol. 63, 1650-1653 (1967).

157. Batteiger, B.E. et al. Partial protection against genital reinfection by immunization of guinea-pigs with isolated outer-membrane proteins of the chlamydial agent of guinea-pig inclusion conjunctivitis. J. Gen. Microbiol. 139 (Part 12), 2965-2972 (1993).

158. Brunham, R.C. \& Peeling, R.W. Chlamydia trachomatis antigens: role in immunity and pathogenesis. Infect. Agents Dis. 3, 218-233 (1994).

159. Dong-Ji, Z. et al. Priming with Chlamydia trachomatis major outer membrane protein (MOMP) DNA followed by MOMP ISCOM boosting enhances protection and is associated with increased immunoglobulin A and Th1 cellular immune responses. Infect. Immun. 68, 3074-3078 (2000).
160. Su, H., Parnell, M. \& Caldwell, H.D. Protective efficacy of a parenterally administered MOMP-derived synthetic oligopeptide vaccine in a murine model of Chlamydia trachomatis genital tract infection: serum neutralizing lgG antibodies do not protect against chlamydial genital tract infection. Vaccine 13, 1023-1032 (1995).

161. Zhang, D. et al. DNA vaccination with the major outer-membrane protein gene induces acquired immunity to Chlamydia trachomatis (mouse pneumonitis) infection. J. Infect. Dis. 176, 1035-1040 (1997).

162. Pal, S. et al. Vaccination of mice with DNA plasmids coding for the Chlamydia trachomatis major outer membrane protein elicits an immune response but fails to protect against a genital challenge. Vaccine 17, 459-465 (1999).

163. Conlan, J.W. et al. Isolation of recombinant fragments of the major outer-membrane protein of Chlamydia trachomatis: their potential as subunit vaccines. J. Gen. Microbiol. 136, $2013-2020$ (1990).

164. Hayes, L.J. et al. Chlamydia trachomatis major outer membrane protein epitopes expressed as fusions with LamB in an attenuated aro A strain of Salmonella typhimurium; their application as potential immunogens. J. Gen. Microbiol. 137, 1557-1564 (1991).

165. Tan, T.W. et al. Protection of sheep against Chlamydia psittaci infection with a subcellular vaccine containing the major outer membrane protein. Infect. Immun. 58, 3101-3108 (1990).

166. Taylor, H.R. et al. Oral immunization with chlamydial major outer membrane protein (MOMP). Invest. Ophthalmol. Vis. Sci. 29, 1847-1853 (1988).

167. Tuffrey, M., Alexander, F., Conlan, W., Woods, C. \& Ward, M. Heterotypic protection of mice against chlamydial salpingitis and colonization of the lower genital tract with a human serovar $\mathrm{F}$ isolate of Chlamydia trachomatis by prior immunization with recombinant serovar L1 major outer-membrane protein. J. Gen. Microbiol. 138 (Part 8), 1707-1715 (1992).

168. Zhong, G., Smith, G.P., Berry, J. \& Brunham, R.C. Conformational mimicry of a chlamydial neutralization epitope on filamentous phage. J. Biol. Chem. 269, 24183-24188 (1994).

169. McNeilly, C.L. et al. Expression library immunization confers partial protection against Chlamydia muridarum genital infection. Vaccine 25, 2643-2655 (2007).

170. Stephens, R.S. Chlamydial genomics and vaccine antigen discovery J. Infect. Dis. 181, S521-S523 (2000).

171. Kalman, S. et al. Comparative genomes of Chlamydia pneumoniae and C. trachomatis. Nat. Genet. 21, 385-389 (1999).

172. Stephens, R.S. et al. Genome sequence of an obligate intracellular pathogen of humans: Chlamydia trachomatis [see comments]. Science 282, 754-759 (1998).

173. Murdin, A.D. et al. Use of a mouse lung challenge model to identify antigens protective against Chlamydia pneumoniae lung infection. J. Infect. Dis. 181 (Suppl 3), S544-S551 (2000).

174. Rosenthal, K.S. \& Zimmerman, D.H. Vaccines: all things considered. Clin. Vaccine Immunol. 13, 821-829 (2006).

175. Pal, S. et al. Immunization with the Chlamydia trachomatis mouse pneumonitis major outer membrane protein can elicit a protective immune response against a genital challenge. Infect. Immun. 69, 6240-6247 (2001).

176. Berry, L.J. et al. Transcutaneous immunization with combined cholera toxin and $\mathrm{CpG}$ adjuvant protects against Chlamydia muridarum genital tract infection. Infect. Immun. 72, 1019-1028 (2004).

177. Eko, F.O. et al. Recombinant Vibrio cholerae ghosts as a delivery vehicle for vaccinating against Chlamydia trachomatis. Vaccine 21, 1694-1703 (2003).

178. Pal, S., Peterson, E.M. \& de la Maza, L.M. Vaccination with the Chlamydia trachomatis major outer membrane protein can elicit an immune response as protective as that resulting from inoculation with live bacteria. Infect. Immun. 73, 8153-8160 (2005).

179. Pal, S. et al. Immunization with the Chlamydia trachomatis major outer membrane protein, using adjuvants developed for human vaccines, can induce partial protection in a mouse model against a genital challenge. Vaccine 24, 766-775 (2006).

180. Pal, S., Peterson, E.M. \& de la Maza, L.M. Vaccination of newborn mice induces a strong protective immune response against respiratory and genital challenges with Chlamydia trachomatis. Vaccine $23,5351-5358$ (2005).

181. Singh, S.R. et al. Mucosal immunization with recombinant MOMP genetically linked with modified cholera toxin confers protection against Chlamydia trachomatis infection. Vaccine 24, 1213-1224 (2006). 
182. Pal, S., Peterson, E.M. \& de la Maza, L.M. Induction of protective immunity against a Chlamydia trachomatis genital infection in three genetically distinct strains of mice. Immunology 110, 368-375 (2003).

183. Lyons, J.M. et al. Comparison of multiple genital tract infections with Chlamydia trachomatis in different strains of female mice. J. Microbiol. Immunol. Infect. 38, 383-393 (2005).

184. Eko, F.O. et al. A novel recombinant multisubunit vaccine against Chlamydia. J. Immunol. 173, 3375-3382 (2004).

185. Su, H. et al. Subclinical chlamydial infection of the female mouse genital tract generates a potent protective immune response: implications for development of live attenuated chlamydial vaccine strains. Infect. Immun. 68, 192-196 (2000).

186. Macmillan, L. et al. A recombinant multivalent combination vaccine protects against Chlamydia and genital herpes. FEMS Immunol. Med. Microbiol. 49, 46-55 (2007).

187. He, Q. et al. Live-attenuated influenza viruses as delivery vectors for Chlamydia vaccines. Immunology 122, 28-37 (2007).

188. Pal, S. et al. Immunization with the Chlamydia trachomatis major outer membrane protein, using the outer surface protein A of Borrelia burgdorferi as an adjuvant, can induce protection against a chlamydial genital challenge. Vaccine 21, 1455-1465 (2003).

189. Lyons, J.M. et al. Acquired homotypic and heterotypic immunity against oculogenital Chlamydia trachomatis serovars following female genital tract infection in mice. BMC Infect. Dis. 5, 105-113 (2005).

190. Murthy, A.K. et al. Chlamydial protease-like activity factor induces protective immunity against genital chlamydial infection in transgenic mice that express the human HLA-DR4 allele. Infect. Immun. 74, 6722-6729 (2006).

191. Murthy, A.K. et al. Intranasal vaccination with a secreted chlamydial protein enhances resolution of genital Chlamydia muridarum infection, protects against oviduct pathology, and is highly dependent upon endogenous gamma interferon production. Infect. Immun. 75, 666-676 (2007).

192. Cong, Y. et al. Intranasal immunization with chlamydial protease-like activity factor and CpG deoxynucleotides enhances protective immunity against genital Chlamydia muridarum infection. Vaccine 25, 3773-3780 (2007).

193. Starnbach, M.N. et al. An inclusion membrane protein from Chlamydia trachomatis enters the MHC class I pathway and stimulates a CD8+ $\mathrm{T}$ cell response. J. Immunol. 171, 4742-4749 (2003).

194. Roan, N.R. et al. Monitoring the T cell response to genital tract infection. Proc. Natl. Acad. Sci. USA 103, 12069-12074 (2006).

195. Fling, S.P. et al. CD8+ T cells recognize an inclusion membraneassociated protein from the vacuolar pathogen Chlamydia trachomatis. Proc. Natl. Acad. Sci. USA 98, 1160-1165 (2001).

196. Whittum-Hudson, J.A. et al. The anti-idiotypic antibody to chlamydial glycolipid exoantigen (GLXA) protects mice against genital infection with a human biovar of Chlamydia trachomatis. Vaccine 19, 4061-4071 (2001).

197. Donati, M. et al. DNA immunization with pgp3 gene of Chlamydia trachomatis inhibits the spread of chlamydial infection from the lower to the upper genital tract in $\mathrm{C} 3 \mathrm{H} / \mathrm{HeN}$ mice. Vaccine 21, 1089-1093 (2003). 